\title{
Polyphenol oxidase as a biochemical seed defense mechanism
}

\author{
E. Patrick Fuerst ${ }^{1}$, Patricia A. Okubara ${ }^{2}$, James V. Anderson ${ }^{3}$ and Craig F. Morris ${ }^{4}$ \\ 'Department of Crop and Soil Sciences, Washington State University, Pullman, WA, USA \\ ${ }^{2}$ Root Disease and Biological Control Research Unit, United States Department of Agriculture - Agricultural Research Service, Washington State University, \\ Pullman, WA, USA \\ ${ }^{3}$ Biosciences Research Laboratory, United States Department of Agriculture - Agricultural Research Service, Fargo, ND, USA \\ ${ }^{4}$ Western Wheat Quality Laboratory, United States Department of Agriculture - Agricultural Research Service, Washington State University, Pullman, WA, USA
}

\section{Edited by:}

Michael L. Sullivan, United States Department of Agriculture, USA

\section{Reviewed by:}

Matthew Escobar, California State University San Marcos, USA

Paul-Camilo Zalamea, Smithsonian

Tropical Research Institute, Panama

\section{*Correspondence:}

E. Patrick Fuerst, Department of Crop and Soil Sciences, Washington State University, E-202 Food Quality Building, Pullman, WA 99164-6394, USA

e-mail:pfuerst@wsu.edu
Seed dormancy and resistance to decay are fundamental survival strategies, which allow a population of seeds to germinate over long periods of time. Seeds have physical, chemical, and biological defense mechanisms that protect their food reserves from decay-inducing organisms and herbivores. Here, we hypothesize that seeds also possess enzyme-based biochemical defenses, based on induction of the plant defense enzyme, polyphenol oxidase (PPO), when wild oat (Avena fatua L.) caryopses and seeds were challenged with seed-decaying Fusarium fungi. These studies suggest that dormant seeds are capable of mounting a defense response to pathogens. The pathogen-induced PPO activity from wild oat was attributed to a soluble isoform of the enzyme that appeared to result, at least in part, from proteolytic activation of a latent PPO isoform. PPO activity was also induced in wild oat hulls (lemma and palea), non-living tissues that cover and protect the caryopsis. These results are consistent with the hypothesis that seeds possess inducible enzyme-based biochemical defenses arrayed on the exterior of seeds and these defenses represent a fundamental mechanism of seed survival and longevity in the soil. Enzymebased biochemical defenses may have broader implications since they may apply to other defense enzymes as well as to a diversity of plant species and ecosystems.

\section{Keywords: seed defense, seed decay, seed longevity, weed seed bank}

\section{SEED SURVIVAL AND LONGEVITY}

Seed decay has been defined as "A process in which the physical integrity of a seed is degraded, ultimately leading to death" (Long et al., 2014). Seed dormancy and resistance to decay are fundamental survival strategies which allow a population of seeds to germinate over time both within and across years (Baskin and Baskin, 2006; Dalling et al., 2011; Long et al., 2014). Thus, seed dormancy and resistance to decay are core components of plant population ecology across a diversity of natural- and agroecosystems. The nutritional reserves of plant seeds are obviously in demand by a great diversity of herbivores and microorganisms. Therefore defenses against such organisms are required for seed survival in the soil.

In agro-ecosystems, weeds cause over $\$ 20$ billion annually in crop damage and losses in the US (Pimentel et al., 2005). Seed dormancy and resistance to decay have a major economic impact due to the longevity of weed seeds in the "soil seed bank." Weed seeds persist in the soil seed bank of agro-ecosystems in astonishing numbers often exceeding $10,000 / \mathrm{m}^{2}$ (Baskin and Baskin, 2006). Seeds commonly survive for years or decades, depending on the species and environment. Wild oat (Avena fatua L.), a model for our research, is shown in Figure 1A as the seed and dissected into caryopsis and hulls (lemma and palea). Wild oat has a longevity of 2-9 years in situ, depending upon environment and cropping system (Beckie et al., 2012); genetic diversity for dormancy in wild oat probably also contributes to variable longevity (Naylor and Fedec, 1978). There are few cases where targeting the dormant weed seed bank has been proven effective and economical (Davis, 2006). Therefore, ecological approaches to alter seed dormancy, viability, and/or longevity that promote weed seed decay could lead to novel biological control alternatives.

In proposing a "seed defense theory," Dalling et al. (2011) state that seeds have four mechanisms of resistance to decay: "(i) physical barriers that render seeds impermeable to pathogens; (ii) endogenous chemical defenses of seeds; (iii) chemical defenses of beneficial seed-microbial associations; and (iv) rapid seed germination." For seeds with physiological dormancy, Dalling etal. (2011) predicted that "microbial and chemical defenses, if present, will be arrayed on the exterior of the seed" and there are indeed reports of secondary chemical defenses (e.g., phenolics, tannins) associated with seed coats (Hendry etal., 1994; Gallagher et al., 2010). There are also reports of bacteria and fungi associated with seed surfaces that may contribute to seed defense (Chee-Sanford etal., 2006; Gallery etal., 2007, 2010; Chee-Sanford, 2008; Dalling et al., 2011; Long et al., 2014). Seeds with physical dormancy (impermeable seed coat or fruit wall) were predicted to rely on physical defenses against predators and pathogens (Dalling et al., 2011). 


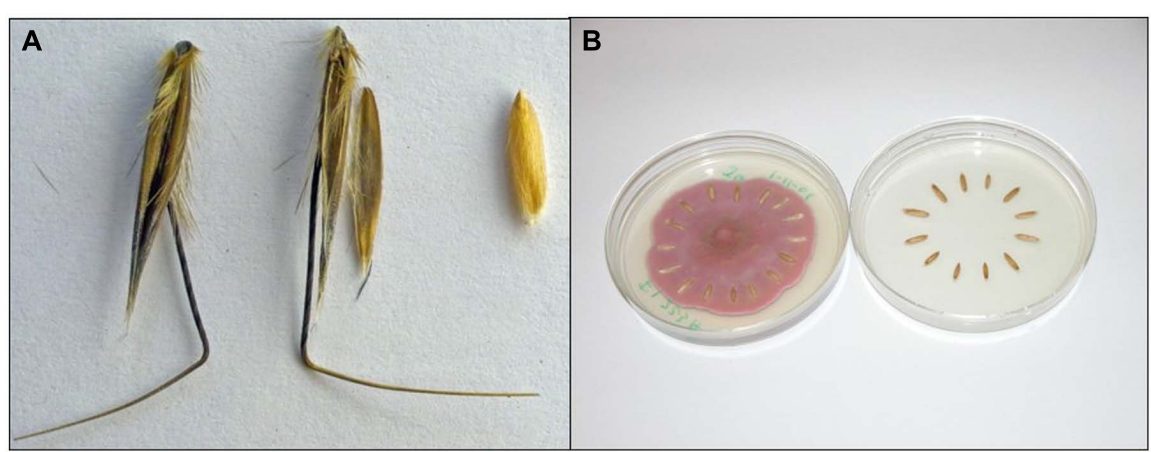

FIGURE 1 | Seeds and pathogen: experimental materials. (A) Wild oat isoline 'M73': seed (left), dissected (middle) into lemma with awn, and palea, and caryopsis (right). We refer to lemma and palea as "hulls." When we refer to wild oat "seeds" we are referring to intact seeds, not to "caryopses."
(B) "Model system," method of incubation of wild oat caryopses on Fusarium avenaceum strain F.a.1. (left) and untreated control (right). Wild oat M73 was chosen as the subject based on extreme dormancy level (Naylor and Fedec, 1978), allowing extended incubations.
As a fifth defense mechanism, we hypothesize that seeds with physiological dormancy, such as wild oat, also possess enzyme-based biochemical defenses arrayed on the exterior of seeds. This proposed "biochemical" mechanism, based on defense enzymes, is distinct from the "chemical" mechanism which is attributed to lower molecular weight, non-protein secondary chemical defenses mentioned above. Consistent with this hypothesis, and as discussed in more detail below, we have shown that wild oat caryopses possess a defense enzyme, polyphenol oxidase (PPO), that is (1) induced by Fusarium seed-decay strains, (2) released from the caryopsis surface following challenge by Fusarium avenaceum strain 'F.a.1' and (3) processed and activated, possibly by a protease (Anderson et al., 2010; Fuerst et al., 2011) following F.a.1 challenge. Furthermore, preliminary results suggest that three additional defense-response enzymes, peroxidase, oxalate oxidase, and chitinase, are induced by F.a.1 challenge. Our objectives here are to (1) review literature relevant to the seed defense enzyme hypothesis, especially information about PPO, but also some background on peroxidase, oxalate oxidase, and chitinase, (2) summarize our research on defense enzymes in cereals, specifically PPO induction in wild oat, (3) present an analysis of transit and signal sequences of seed PPOs of wheat (Triticum aestivum L.), and (4) present experimental questions implied by this new hypothesis. Seed longevity in the soil is not a major concern in wheat because wheat has relatively little dormancy and germinates rapidly, the result of domestication and plant breeding. However, our knowledge base for the biochemistry and genetics of defense enzymes in wheat, especially PPO and peroxidase, is far more extensive than in wild oat. Much of the information obtained in wheat may apply not only to wild oat seeds but also to seeds of many other species, and may therefore provide tools for understanding biochemical and molecular signaling in seed-pathogen interactions.

\section{CHARACTERISTICS OF PPO AND SEED DEFENSE ENZYMES}

In order to be maximally effective in promoting seed longevity, PPO and other potential seed defense enzymes would need to be extrinsic (on or near the seed surface), bound or slowly released, durable, and capable of expressing activity after years of survival in the soil. PPO and peroxidase appear to possess many of these properties in wheat, in which they are primarily associated with the outer surface, as indicated by their high levels in the bran fraction when milling wheat (Fraignier et al., 2000; Rani et al., 2001). In vitro studies indicate that PPO and peroxidase are heat-tolerant (Vadlamani and Seib, 1996) and oxalate oxidase is tolerant of heat, protease, and detergents (Liang etal., 2001). Wheat PPO is predominantly present as an insoluble enzyme (Fuerst et al., 2006), perhaps available for activation and release by mechanisms discussed in this paper. The "whole kernel" PPO assay that we have utilized extensively (AACC International, 2000; Anderson and Morris, 2001; Fuerst et al., 2010) is indeed based on the extrinsic property of PPO on the wheat kernel. We have also observed that peroxidase and oxalate oxidase activities are readily measured by the same method in wheat (Fuerst, unpublished data), also implying their presence on the outer surface. Genetic studies are also consistent with PPO contributing to defense on the extrinsic surfaces of the seed: PPO activity and darkening of seed coat were strongly associated in recombinant inbred lines of pinto bean (Phaseolis vulgaris L.; Marles et al., 2008) and PPO was strongly associated with dark color of lemma and palea in Setaria spp. (Till-Bottraud and Brabant, 1990).

Polyphenol oxidases, peroxidases, and oxalate oxidases appear to have many properties in common that are relevant to seed defense. Isoforms of PPOs, peroxidases, and oxalate oxidases (1) are considered to be plant defense enzymes, (2) are involved in metabolism of oxygen and reactive oxygen species, (3) carry out the synthesis of low molecular weight defense compounds, (4) contribute to cross-linking of the extracellular matrix, (5) are considered heat-stable, and (6) are found on the exterior of seeds (Mayer, 2006; Dunwell et al., 2008; Almagro et al., 2009; Jerkovic et al., 2010). However, differences among these three enzymes include their metal co-factors: copper for PPO, manganese for oxalate oxidase, and iron for peroxidase, as well as their complementary roles in oxidative stress metabolism. For instance, oxalate oxidases generate hydrogen peroxide, and peroxidases use hydrogen peroxide as a substrate. 
Perhaps the most compelling case for the extrinsic localization of defense enzymes was presented by Jerkovic et al. (2010). Proteomic studies demonstrated a great abundance and diversity of defense proteins in microdissected bran layers of wheat. Such proteins include the four enzyme types that we discuss here, PPO, peroxidase, oxalate oxidase, and chitinase; enzymatic activities of these enzymes were also demonstrated in water-soluble proteins from pericarp tissue and/or whole grains.

\section{HOST DEFENSE RESPONSES}

Polyphenol oxidases are commonly associated with plant defense (Mayer, 2006; Constabel and Barbehenn, 2008). In many plant tissues, increased abundance of PPO transcripts in response to wounding and plant defense-related hormones such as systemin, salicylic acid, and jasmonates suggest that PPO genes are induced as part of a general defense response in plants (Constabel et al., 1998; Mayer, 2006; Flurkey and Inlow, 2008). PPOs are induced in incompatible (resistant) plant-pathogen interactions, including tomato Fusarium wilt, wheat head blight, potato late blight, and potato bacterial wilt (Mohammadi and Kazemi, 2002; Ramamoorthy et al., 2002; Thipyapong et al., 2007; Poiatti et al., 2009). PPOs are also induced in compatible (susceptible) interactions, such as potato soft rot and in non-host interactions, such as bacterial spot of citrus in potato. A direct link of PPO with disease severity and herbivore growth was demonstrated in PPO over-expressing and anti-sense genotypes of tomato, in which susceptibility to disease and herbivory were closely linked to the increased or decreased foliar PPO activities, respectively (Thipyapong et al., 2007). This induction of PPOs by a broad spectrum of pathogens and the relationship between PPO activities and susceptibility to disease and herbivory suggests that PPOs are part of plant innate immunity.

Peroxidase, oxalate oxidase, and chitinase, in addition to PPO, are among the defense enzymes induced in roots and foliage during challenge with fungal pathogens, and all are usually encoded by multi-gene families (reviewed in Lane, 2002; van Loon et al., 2006; Hücklehoven, 2007; Dunwell et al., 2008). All four enzymes participate in cell wall-associated host defense (Hücklehoven, 2007), the first line of defense against pathogen invasion, and all are expressed in seeds (Lane, 1994; Leah et al., 1994; Laugesen et al., 2007; Beecher et al., 2012).

Peroxidase is induced in tomato leaves infected with F. oxysporum, f. sp. lycopersici, Pseudomonas syringae and other pathogens, and by wounding (Ramamoorthy et al., 2002; Thipyapong et al., 2007). The class III peroxidases involved in host defense are wound- and pathogen-inducible, but in tobacco, peroxidase activity is not directly regulated by the defense phytohormones jasmonic acid and salicylic acid (Hiraga et al., 2001). In contrast, host oxalate oxidases are induced during interactions with biotrophic pathogens but not by wounding (Dumas et al., 1995; Zhang et al., 2013), suggesting different regulatory pathways among PPO, peroxidase, and oxalate oxidase, at least in leaves.

Class III peroxidases are secreted plant proteins with a remarkable number of functions including cross-linking cell wall polymers and lignification (Passardi et al., 2005; Almagro etal., 2009; Cosio and Dunand, 2009). Their role in defense is due to strengthening cell walls and massive production of reactive oxygen species. Oxalate oxidases ('germins') are a component of defense signaling in cereals (Lane etal., 1993; Hurkman and Tanaka, 1996; Dunwell etal., 2008) and have dual defense activities including the catabolism of fungal-derived oxalic acid, a metabolite toxic to plants, and production of fungicidal levels of hydrogen peroxide (Lane, 2002). Chitinases hydrolyze polymers containing $\mathrm{N}$-acetylglucosamine such as chitin found in fungal cell walls, and are often associated with antifungal activity (Yan et al., 2008; Grover, 2012).

\section{BIOCHEMISTRY}

Polyphenol oxidases utilize molecular oxygen to catalyze the hydroxylation and dehydrogenation of phenolic compounds to form reactive $o$-quinones, which alkylate nucleophilic groups and self-polymerize to form dark-colored melanin polymers. Most plant PPOs are capable of oxidizing a broad spectrum of $\boldsymbol{o}$-phenolics. Haruta etal. (2001) reported that catechol derived from phenolic glycosides was likely a substrate involved in PPO-mediated herbivore defense and Marles et al. (2008) indicated that flavonols and condensed tannins, potential PPO substrates, are associated with seed coat darkening, but few other in planta substrates are known (Constabel and Barbehenn, 2008). Most plant PPOs are sequestered as latent enzymes in the chloroplast whereas most PPO substrates are located in other subcellular compartments. Cell disruption by herbivores and pathogens would allow PPO and its substrates to co-mingle; PPO-mediated reactions would then be maximized if PPO is activated. Likewise, disruption of this compartmentation is what leads to browning reactions in many fresh and processed food products, the result of PPOmediated melanin polymer formation (Yoruk and Marshall, 2003; Mayer, 2006).

Nascent, unprocessed preproteins frequently contain $\mathrm{N}$ terminal peptide sequences of $\sim 20-60$ amino acids that facilitate protein translocation from the site of synthesis in the cytoplasm to the subcellular target. Proteins targeted for chloroplast and mitochondria contain 'transit peptides' and proteins targeted for secretion via the endoplasmic reticulum contain 'signal peptides' (Gutensohn et al., 2006; Imai and Nakai, 2010; Yan and Wu, 2014). Although chloroplast transit peptides have been most commonly associated with unprocessed PPOs, PPO signal peptides for secretion have also been identified and vacuolar localization has been demonstrated in two species, Antirrhinum majus L. (snapdragon) and Populus trichocarpa Torr. and A. Gray (Western balsam poplar; Tran et al., 2012). The presence of signal peptides suggests that targeting other subcellular locations such as the extracellular space, might play a role in defense near the seed surface.

Four potential mechanisms by which PPO may inhibit pathogens and herbivores include (1) toxicity and antimicrobial activity of quinone products, (2) reduced bioavailability of proteins and nutrients, (3) creating lignin-like physical barriers, and (4) participating in the production of reactive oxygen species (Constabel and Barbehenn, 2008).

Most unprocessed plant PPOs range from $\sim 68-73 \mathrm{kDa}$, which contain an $N$-terminal transit peptide that is cleaved to produce 
a 55-68 kDa "mature" protein during transport into the chloroplast (van Gelder et al., 1997). These mature forms of plant PPOs are often latent or only partially active and proteolytic cleavage of a $C$-terminal peptide generally produces an active $\sim 37-44 \mathrm{kDa}$ PPO (van Gelder et al., 1997; Mayer, 2006; Flurkey and Inlow, 2008). However, harsh in vitro treatments including detergents, solvents, chaotropes, and proteolysis are also known to activate latent forms of PPO (Steffens et al., 1994; Flurkey and Inlow, 2008; Fuerst et al., 2010). Thus, mature plant PPOs are able to tolerate extreme changes in their environment, which likely explains the apparent stability of PPOs on the surface of seeds.

\section{GENETICS AND REGULATION OF PPOS AND DEFENSE ENZYMES}

Most PPOs are encoded by multigene families whose members exhibit organelle-, tissue-, and development-specific expression (Steffens et al., 1994; Thygesen et al., 1995; Anderson et al., 2006; Beecher et al., 2012; Tran et al., 2012). Tomato (Lycopersicum esculentum L.) harbors seven genes encoded at a single locus on Chromosome 8; one, PPO F, is associated with defense in the leaves (Thipyapong et al., 1997; Newman et al., 2011). Developing tubers of potato (Solanum tuberosum L.) express five PPO genes, similarly clustered on Chromosome 8 (Thygesen et al., 1995; Thipyapong etal., 1997). The clustering of PPO genes in tomato and potato are considered to reflect their evolutionary origin via gene duplication. Diversity in gene number, sequence, tissue specificity, and substrate specificity across plant species suggest that the PPOs have long-term roles in fitness, niche adaptation and/or adaptation to environmental factors (Tran et al., 2012).

The transcriptional regulation of PPO genes is implied from the spatial and temporal expression patterns of gene family members in wheat, tomato, and potato (Thygesen et al., 1995; Thipyapong et al., 1997; Anderson et al., 2006; Beecher et al., 2012). Seedexpressed members of the PPO, peroxidase, oxalate oxidase, and chitinase enzyme families, particularly those expressed in the seed coat and aleurone, are especially relevant to our seed defense hypothesis. At least four to five distinct PPOs are expressed in seeds (caryopses) of hexaploid wheat (Massa et al., 2007; Beecher et al., 2012). These seed-expressed genes are clustered on Chromosome 2 of all three of the A, B, and D ancestral genomes (Beecher et al., 2012). In addition, the wheat seed-expressed PPO genes and other PPO genes usually contain introns (Massa et al., 2007; Beecher et al., 2012; Tran et al., 2012). The promoter of tomato PPO $B$ regulates a family member expressed in the ovule seed coat and endosperm and harbors cis-acting elements responsive to phytohormones (ethylene, jasmonic acid, and gibberellic acid), associated with seed expression, and cAMP signaling (Newman et al., 2011). However, there is limited knowledge about transcriptional regulation of PPO in the seed coats of cereals. Analysis of promoters of seed-expressed wheat and wild oat orthologs would be informative when whole genome sequence data are available.

Examples in which other defense enzymes are expressed in seeds include four peroxidase proteins in barley aleurone (Laugesen et al., 2007), chitinase in barley aleurone (Leah et al., 1994), and oxalate oxidase associated with seed germination (Lane et al., 1991; Berna and Bernier, 1997). Isoforms of all four defense proteins have been localized to the seed coat or extracellular matrix of soybean (Gijzen et al., 1993; Lane, 1994; Gijzen et al., 2001), suggesting their potential defense roles in seeds. Likewise all four proteins and enzymatic activities were demonstrated to be associated with the extrinsic bran layers of wheat (Jerkovic et al., 2010), as previously discussed.

\section{DEFENSE ENZYMES IN WILD OAT AND WHEAT}

We hypothesized, above, that seeds possess enzyme-based biochemical defenses arrayed on or near the exterior of seeds as a mechanism of resistance to seed decay, contributing to seed longevity in the soil. Consistent with this hypothesis, caryopsis PPO activity was induced by three Fusarium strains, although activity was also inhibited by a Pythium strain (Fuerst et al., 2011). Fusarium avenaceum strain F.a.1 caused the most rapid decay and the greatest induction of PPO. Wild oat seed and components are shown in Figure 1A. When whole wild oat seeds were incubated on F.a.1, PPO activity was induced in the whole seeds as well as in the dissected components: the hulls (lemma and palea) and caryopses. The induction of PPO activity in the hulls was surprising for a non-living tissue; however, latent PPO forms may be activated on the hulls in the same manner as in caryopses, as discussed below. F.a.1 induction of PPO in caryopses was greater than in intact seeds, and occurred more rapidly as well. Therefore our subsequent work focused on the F.a.1-wild oat caryopsis 'model system' (Figure 1B). PPO activity of F.a.1-treated caryopses was readily washed off, whereas very little PPO activity could be leached from untreated caryopses. This led to a series of studies on "caryopsis leachates," focusing on that part of the PPO that was activated by F.a.1.

We hypothesized that F.a.1-induced PPO activation in wild oat caryopses involved proteolytic cleavage that simultaneously activated and solubilized PPOs (Figure 2). This hypothesis was tested utilizing protein fractionation, immunoblots (westerns), and peptide sequencing (Anderson et al., 2010). The predominant form of PPO obtained from untreated wild oat caryopses and leachates was an inactive $\sim 57 \mathrm{kD}$ protein. Leachate from F.a.1treated caryopses had a decreased abundance of the $\sim 57 \mathrm{kDa}$ PPO and increased abundance of PPOs ranging from $\sim 52-14 \mathrm{kDa}$; these changes were associated with significant increases in both total activity and specific activity of PPO. The majority of PPO activity from untreated and F.a.1-treated caryopses was associated with a $\sim 36 \mathrm{kDa}$ protein. However, the F.a.1-treated caryopsis leachates also had PPO activity associated with $\sim 25$, and $\sim 24 \mathrm{kDa}$ proteins. Protein sequencing confirmed that the inactive $\sim 57 \mathrm{kD}$ and activated $\sim 36 \mathrm{kD}$ wild oat proteins were homologous to known PPO sequences. Results also suggested that activation of wild oat PPO involved the cleavage of a $C$-terminal peptide, consistent with proteolytic PPO activation in other plant systems (Flurkey and Inlow, 2008). These results support our hypothesis that mature, latent PPO is simultaneously activated and released into the environment, likely by proteolytic cleavage, as part of a defense mechanism during pathogen attack in wild oat caryopses.

Interestingly, peptide sequencing of the 25 and $\sim 24 \mathrm{kDa}$ proteins obtained from F.a.1-treated wild oat were most similar to a chitinase and oxalate oxidase, respectively (Anderson et al., 2010). Furthermore, separate preliminary studies demonstrated 


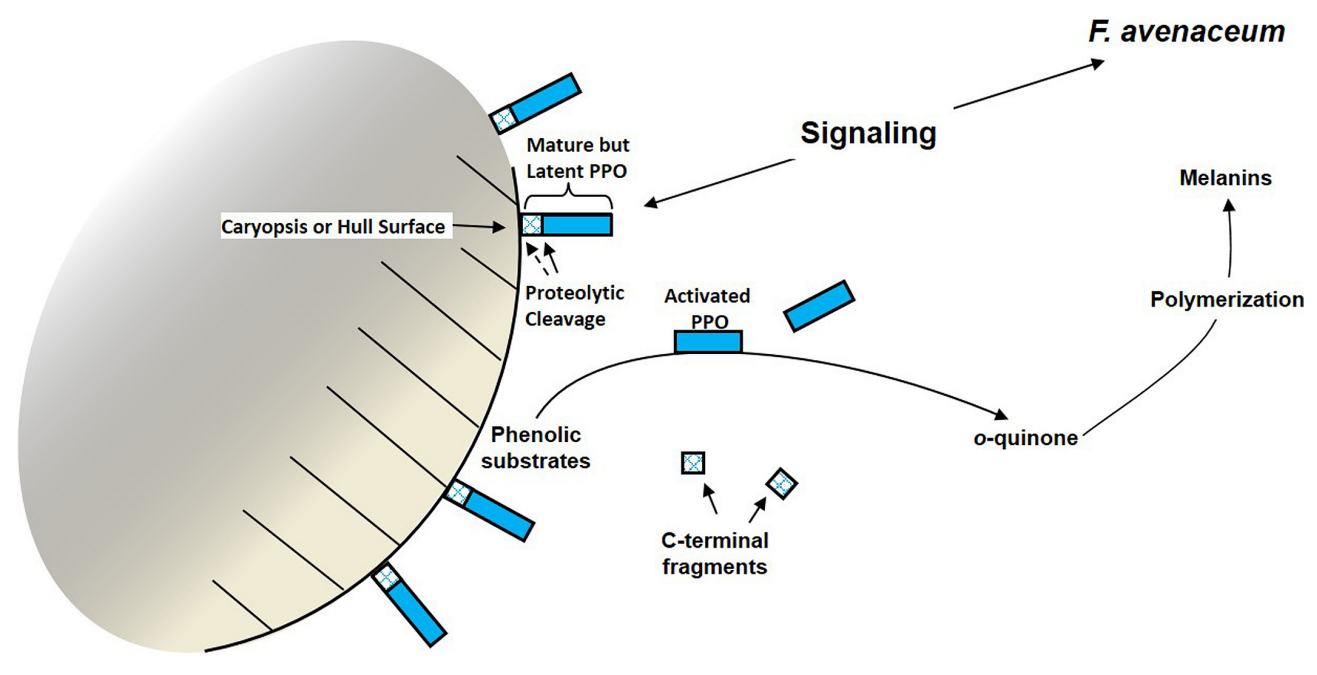

FIGURE 2 | Model for simultaneous activation and release of constitutive polyphenol oxidase (PPO) by proteolysis on the surface of a wild oat caryopsis following pathogen challenge. Such a mechanism would not exclude PPO induction by other mechanisms, such as transcriptional induction. Both o-quinones and melanins are hypothesized to have anti-microbial properties (Constabel and Barbehenn, 2008). that F.a.1-treatment increased peroxidase activity in leachates approximately sixfold (Fuerst, unpublished data). Collectively, these observations suggested that multiple defense enzymes were induced by F.a.1 in wild oat caryopses.

\section{PPO TRANSIT AND SIGNAL PEPTIDES}

The known and deduced amino acid sequences of PPO are informative for predicting plastidic or extracellular localization of mature proteins, hence distinguishing PPOs with potential for export and activation beyond the plasma membrane. Proteins harboring chloroplast transit peptides may not be mobilized without cell lysis, whereas proteins harboring extracellular signal peptides may be relevant to PPOs that reside on the surface of seeds or are transcriptionally induced as part of a defense system upon pathogen challenge. Whether constitutive and inducible defense activities can operate in parallel remains to be determined, but the possibility for this can be hypothesized if certain PPOs have chloroplast transit peptides and others have extracellular signal peptides. Several procedures for identifying different types of transit and signal peptides are available (Imai and Nakai, 2010). To test the hypothesis that wheat and other grasses encode PPO preproteins harboring signal peptides with potential for extracellular secretion, we conducted an in silico analysis of 12 wheat, one barley, and one Brachypodium distachyon protein sequences.

\section{MATERIALS AND METHODS}

Analysis for the presence of extracellular signal peptides was conducted primarily using wheat proteins because genome sequence and transcriptome data were readily available for wheat but not for wild oat. Three web-based programs were used: SignalP 4.1 for prediction of signal peptides in eukaryotic proteins (Petersen et al., 2011), TargetP 1.1 for prediction of peptides for chloroplastic, mitochondrial or extracellular localization (Emanuelsson et al., 2000), and Signal-3L for prediction of signal peptides in plants (Shen and Chou, 2007). SignalP 4.1 predicted the secretory signal peptide cleavage site ( $C$-score and $S$-score), and distinguished amino acids within a signal peptide from those in the processed protein ( $Y$-score). The TargetP algorithm differentiated chloroplastic and mitochondrial transit peptides from signal peptides. TargetP reliability class (RC) values were assigned on a scale of $1-5$, where 1 reflected the strongest prediction. The nominal RC values were based on differences between the most probable and next most probable output score. The Signal-3L output was qualitative ('yes' or 'no' for a signal peptide).

Amino acid sequences of ten seed-expressed PPOs from two wheat species (Beecher et al., 2012) were analyzed. A total of four additional monocot PPO sequences also were analyzed. One was a novel candidate PPO retrieved from the International Wheat Genome Sequencing Consortium [IWGSC] (2014) nucleotide sequence database. The PPO open reading frame was found at the $3^{\prime}$ end of IWGSC accession chr4DL_V3_ab_k71_14468617 using Blastn (Altschul et al., 1997) and the open reading frames of GenBank accessions JN632506 (PPO-A1h) and JN632507 (PPO$\mathrm{A} 2 \mathrm{c})$ as query sequences. The deduced amino acid sequence of the IWGSC accession, designated IWGSC seg6A, was identified by alignments with two closely-related sequences from GenBank, a predicted protein from barley (AK358933; Matsumoto et al., 2011) and a PPO from Brachypodium distachyon (XM_003564319.1). Both the barley and B. distachyon sequences were included in the analyses. Finally, a second PPO genomic sequence from wheat $\mathrm{cv}$. Chinese Spring was retrieved from GenBank (AB254806). The secreted protein cysteine proteinase RD21A (At1g47128) from Arabidopsis thaliana served as a control.

\section{RESULTS AND DISCUSSION}

The SignalP 4.1 $C$-scores and $S$-scores for ten wheat seed-expressed PPO proteins ranged from $0.110-0.206$ and $0.130-0.191$, respectively. These were close to the ideal scores for a non-extracellular 
protein (Table 1). The SignalP $Y$-scores were also below the threshold for extracellular signal peptides. Absence of signal peptides was confirmed by Signal-3L (data not shown) and TargetP 1.1. A secretory signal peptide was strongly indicated as expected in the control cysteine proteinase RD21A, using the SignalP (Table 1) and Signal-3L analyses. Chloroplast transit peptides were predicted to occur in all ten wheat seed PPOs by TargetP 1.1 (Table 1). Chloroplast transit peptide scores were 0.60 or higher, whereas mitochondrial targeting peptide scores were below 0.52 . The $\mathrm{RC}$ values were $2-4$, reflecting intermediate prediction reliability values $(1=$ strongest prediction). The difference in RC values between the wheat PPO and the Arabidopsis control might reflect a bias in the TargetP algorithm for Arabidopsis proteins. As expected, cysteine proteinase RD21A was not predicted to have a chloroplast or mitochondrial targeting sequence.

For the four additional monocot PPOs, SignalP, general for eucaryotes, predicted signal peptides for wheat AB254806 and Brachypodium XM_003564319.1 but not for the barley AK358933 or the wheat IWGSC seg6A proteins (Table 2). This contrasted with results from TargetP, specific for plant proteins, which predicted that the wheat IWGSC, barley, and Brachypodium PPO proteins carried extracellular signal peptides, but predicted that wheat AB254806 had a chloroplast transit peptide. Signal-3L (data not shown) predicted that all four proteins carried signal peptides. Our overall interpretation of these results favors the TargetP interpretation, which is both specific for plants (unlike SignalP) and clearly delineated chloroplast vs. mitochondrial transit peptides,

Table 1 | In silico analysis of potential chloroplast transit peptide sequences in ten wheat seed-expressed polyphenol oxidases.

\begin{tabular}{|c|c|c|c|c|c|c|c|c|c|}
\hline \multirow[b]{2}{*}{ Allele } & \multirow[b]{2}{*}{ Accession } & \multicolumn{4}{|c|}{ SignalP ${ }^{1}$} & \multicolumn{3}{|c|}{ TargetP2 } & \multirow[b]{2}{*}{ RC } \\
\hline & & $c$ & $\mathbf{S}$ & $\mathbf{Y}$ & Prediction & cTP & mTP & SP & \\
\hline PPO-A1f & EU371654 & 0.115 & 0.181 & 0.323 & no SP & 0.833 & 0.472 & 0.004 & 4 \\
\hline PPO-A2c & JN632507 & 0.206 & 0.191 & 0.358 & no SP & 0.655 & 0.201 & 0.004 & 4 \\
\hline PPO-B2a & HQ228150 & 0.168 & 0.133 & 0.173 & no SP & 0.838 & 0.132 & 0.009 & 3 \\
\hline PPO-B2c & JN632508 & 0.167 & 0.135 & 0.202 & no SP & 0.764 & 0.326 & 0.005 & 3 \\
\hline PPO-D1a & EF070149 & 0.112 & 0.130 & 0.166 & no SP & 0.903 & 0.235 & 0.006 & 2 \\
\hline PPO-D1b & EF070150 & 0.136 & 0.183 & 0.339 & no SP & 0.848 & 0.524 & 0.004 & 4 \\
\hline PPO-D2a & HO228152 & 0.110 & 0.191 & 0.357 & no SP & 0.598 & 0.265 & 0.004 & 4 \\
\hline
\end{tabular}

${ }^{1}$ The $\mathrm{C}$-score and S-score predict signal peptide cleavage sites; the $Y$-score distinguishes amino acids within a signal peptide from those in the processed protein. Low values are associated with non-secreted proteins.

2 High values predict chloroplastic transit peptide (CTP), mitochondrial transit peptide (mTP) or signal peptide (SP). The reliability class (RC) values were on a scale of $1-5$, where 1 is the strongest prediction.

${ }^{3}$ The secreted cysteine proteinase At1g47128 from Arabidopsis thaliana served as a control.

Table 2 | In silico evaluation of potential signal peptides in four monocot polyphenol oxidases.

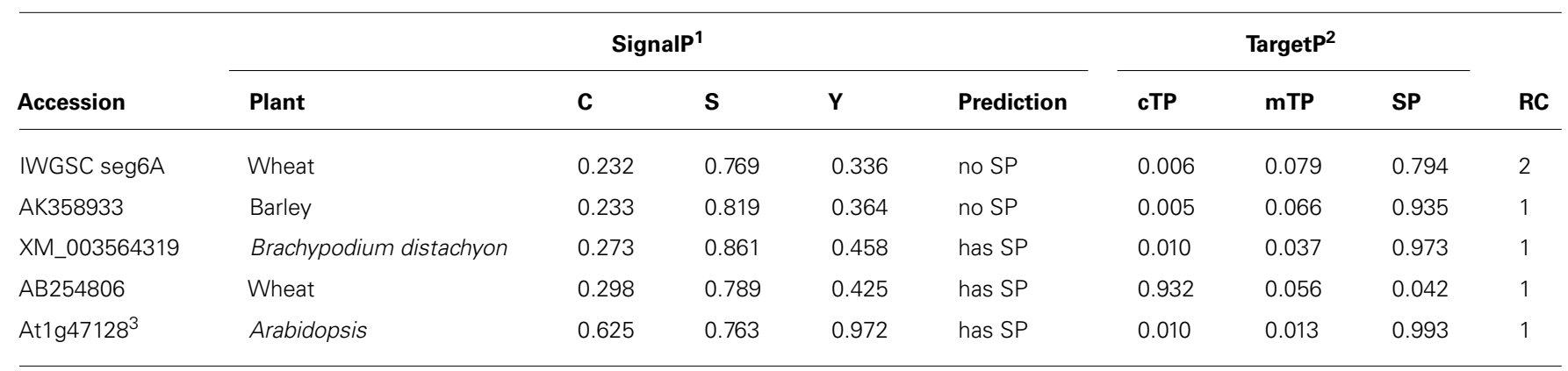

${ }^{1}$ The $\mathrm{C}$-score and S-score predict signal peptide cleavage sites; the Y-score distinguishes amino acids within a signal peptide from those in the processed protein. Low values are associated with non-secreted proteins.

${ }^{2}$ High values predict chloroplastic transit peptide (cTP), mitochondrial transit peptide (mTP) or signal peptide (SP). The reliability class (RC) values were on a scale of $1-5$, where 1 is the strongest prediction.

${ }^{3}$ The secreted cysteine proteinase At1g47128 from Arabidopsis thaliana served as a control. 
whereas Signal-3L appeared less stringent in identifying signal peptides.

Although most plant PPO sequences contain chloroplast transit peptides, some PPO sequences contain $N$-terminal signal peptides for extracellular secretion, as previously discussed. Our results here are consistent with those generalizations, and indicate that signal peptides are probably present in at least one PPO preprotein sequence for each monocot species, wheat (IWGSC seg6A), barley (AK358933), and Brachypodium (XM_003564319.1). The non-chloroplast targeting may include extracellular secretion, a localization possibly related to the apparently extrinsic nature of PPO in wheat and wild oat caryopses (Fuerst et al., 2010, 2011).

\section{FUTURE RESEARCH}

We hypothesize that seeds with physiological dormancy possess extrinsic enzyme-based biochemical defense mechanisms that contribute to seed longevity and survival in the soil. This hypothesis is based upon substantial but very specific evidence of PPO induction in dormant wild oat by the seed decay isolate, F.a.1, preliminary observations that peroxidase, oxalate oxidase, and chitinase may also be part of this defense response, and evidence for the extrinsic localization of defense enzymes especially as reported in wheat (Jerkovic et al., 2010). It is not known how broadly this mechanism applies in nature, and many questions remain, including: (1) In the specific case of PPO induction by F.a.1 in wild oat, is only constitutive (i.e., latent, mature) PPO activated by protease (Figure 2), or are active processes involved in this induction such as de novo PPO transcription and translation? (2) Does the protease come from the seed, or pathogen? (3) Are such defense enzymes widely present in seeds of other plant species including species with both physiological and physical dormancy? (4) Are seed defenses only induced by specific microorganisms, or more generally induced by a diversity of microorganisms including both seed decay pathogens and non-pathogenic microorganisms? (5) Do such enzymes actually contribute to seed defense and longevity in the soil and in the field? (6) Can knowledge of seed defenses and seed-microbe interactions be developed as a technology to enhance management of undesirable species, i.e., to promote the decay and decline of the weed seed bank? With so many unanswered questions, it is clear that this is a noteworthy opportunity for significant fundamental and applied research on enzyme-based biochemical and molecular seed defense mechanisms.

\section{ACKNOWLEDGMENTS}

This project was supported by the Agriculture and Food Research Initiative Grant Number 2013-02322 (Award Number: 201467013-21575) from the USDA National Institute of Food and Agriculture, and by the United States Department of Agriculture, Agricultural Research Service Project Number 5248-22000-01200D (Patricia A. Okubara).

\section{REFERENCES}

AACC International. (2000). Approved Methods of the American Association of Cereal Chemists, 10th Edn. Saint Paul, MN: AACC International.

Almagro, L., Gomez Ros, L. V., Belchi-Navarro, S., Bru, R., Ros Barcelo, A., and Pedreno, M. A. (2009). Class III peroxidases in plant defence reactions. J. Exp. Bot. 60, 377-390. doi: 10.1093/jxb/ern277
Altschul, S. F., Madden, T. L., Schaffer, A. A., Zhang, J., Zhang, Z., Miller, W., et al. (1997). Gapped BLAST and PSI-BLAST: a new generation of protein search programs. Nucleic Acids Res. 25, 3389-3402. doi: 10.1093/nar/25.17.3389

Anderson, J. V., Fuerst, E. P., Hurkman, W. J., Vensel, W. H., and Morris, C. F. (2006). Biochemical and genetic characterization of wheat (Triticum spp.) kernel polyphenol oxidases. J. Cereal Sci. 44, 353-367. doi: 10.1016/j.jcs.2006.06.008

Anderson, J. V., Fuerst, E. P., Tedrow, T., Hulke, B., and Kennedy, A. C. (2010). Activation of polyphenol oxidase in dormant wild oat caryopses by a seed decay isolate of Fusarium avenaceum. J. Agric. Food Chem. 58, 10597-10605. doi: $10.1021 /$ jf102625a

Anderson, J. V., and Morris, C. F. (2001). An improved whole-seed assay for screening wheat germplasm for polyphenol oxidase activity. Crop Sci. 41, 1697-1705. doi: 10.2135/cropsci2001.1697

Baskin, C. C., and Baskin, J. M. (2006). The natural history of soil seed banks of arable land. Weed Sci. 54, 549-557. doi: 10.1614/WS-05-034R.1

Beckie, H. J., Francis, A., and Hall, L. M. (2012). The biology of Canadian weeds. 27. Avena fatua L. Can. J. Plant Sci. 92, 1329-1357. doi: 10.4141/cjps2012-005

Beecher, B. S., Carter, A. H., and See, D. R. (2012). Genetic mapping of new seedexpressed polyphenol oxidase genes in wheat (Triticum aestivum L.). Theor. Appl. Genet. 124, 1463-1473. doi: 10.1007/s00122-012-1801-2

Berna, A., and Bernier, F. (1997). Regulated expression of a wheat germin gene in tobacco: oxalate oxidase activity and apoplastic localization of the heterologous protein. Plant Mol. Biol. 33, 417-419. doi: 10.1023/A:1005745015962

Chee-Sanford, J. C. (2008). Weed seeds as nutritional resources for soil Ascomycota and characterization of specific associations between plant and fungal species. Biol. Fertil. Soils 44, 763-771. doi: 10.1007/s00374-007-0259-x

Chee-Sanford, J. C., Williams, M. M, Davis, A. S., and Sims, G. K. (2006). Do microorganisms influence seed-bank dynamics? Weed Sci. 54, 575-587. doi: 10.1614/WS-05-055R.1

Constabel, C. P., and Barbehenn, R. (2008). "Defensive roles of polyphenol oxidase in plants," in Induced Plant Resistance to Herbivory, ed. A. Schaller (Dordrecht: Springer Science and Business Media B.V.), 253-269. doi: 10.1007/978-1-40208182-8_12

Constabel, C. P., Bergey, D. R., and Ryan, C. A. (1998). A survey of wound- and methyl jasmonate-induced leaf polyphenol oxidase in crop plants. Phytochemistry 47, 507-511. doi: 10.1016/S0031-9422(97)00539-6

Cosio, C., and Dunand, C. (2009). Specific functions of individual class III peroxidase genes. J. Exp. Bot. 60, 391-408. doi: 10.1093/jxb/ ern318

Dalling, J. W., Davis, A. S., Schutte, B. J., and Arnold, A. E. (2011). Seed survival in soil: interacting effects of predation, dormancy and the soil microbial community. J. Ecol. 99, 89-95. doi: 10.1111/j.1365-2745.2010. 01739.x

Davis, A. S. (2006). When does it make sense to target the weed seed bank? Weed Sci. 54, 558-565. doi: 10.1614/WS-05-058R.1

Dumas, B., Freyssinet, G., and Pallett, K. E. (1995). Tissue-specific expression of germin-like oxalate oxidase during development and fungal infection of barley seedlings. Plant Physiol. 107, 1091-1096.

Dunwell, J. M., Gibbings, J. G., Mahmood, T., and Saqlan Naqvi, S. M. (2008). Germin and germin-like proteins: evolution, structure and function. Crit. Rev. Plant Sci. 27, 342-375. doi: 10.1080/07352680802333938

Emanuelsson, O., Nielsen, H., Brunak, S., and von Heijne, G. (2000). Predicting subcellular localization of proteins based on their $\mathrm{N}$-terminal amino acid sequence. J. Mol. Biol. 300, 1005-1016. doi: 10.1006/jmbi.2000.3903

Flurkey, W. H., and Inlow, J. K. (2008). Proteolytic processing of polyphenol oxidase from plants and fungi. J. Inorg. Biochem. 102, 2160-2170. doi: 10.1016/j.jinorgbio.2008.08.007

Fraignier, M. P., Michaux-Ferriere, N., and Kobrehel, K. (2000). Distribution of peroxidases in durum wheat (Triticum durum). Cereal Chem. 77, 11-17. doi: 10.1094/CCHEM.2000.77.1.11

Fuerst, E. P., Anderson, J. V., Kennedy, A. C., and Gallagher, R. S. (2011). Induction of polyphenol oxidase activity in dormant wild oat (Avena fatua) seeds and caryopsis: a defense response to seed decay fungi. Weed Sci. 59, 137-144. doi: 10.1614/WS-D-10-00123.1

Fuerst, E. P., Anderson, J. V., and Morris, C. F. (2006). Polyphenol oxidase in wheat grain: whole-kernel and bran assays for total and soluble activity. Cereal Chem. 83, 10-16. doi: 10.1094/CC-83-0010

Fuerst, E. P., Anderson, J. V., and Morris, C. F. (2010). "Effects of polyphenol oxidase on noodle color: mechanisms, measurement, and improvement," in Asian 
Noodles: Science, Technology, and Processing, Chap. 12, ed. G. G. Hou (Hoboken, NJ: John Wiley \& Sons, Inc.), 285-312.

Gallagher, R. S., Ananth, R., Bradley, B., Granger, K., Anderson, J. V., and Fuerst, E. P. (2010). Phenolic and short-chained aliphatic organic acid constituents of wild oat (Avena fatua L.) seeds. J. Agric. Food Chem. 58, 218-225. doi: 10.1021/jf9038106

Gallery, R. E., Dalling, J. W., and Arnold, A. E. (2007). Diversity, host affinity, and distribution of seed-infecting fungi: a case study with Cecropia. Ecology 88, 582-588. doi: 10.1890/05-1207

Gallery, R. E., Moore, D. J. P., and Dalling, J. W. (2010). Interspecific variation in susceptibility to fungal pathogens in seeds of 10 tree species in the Neotropical genus Cecropia. J. Ecol. 98, 147-155. doi: 10.1111/j.1365-2745.2009.01589.x

Gijzen, M., Kuflu, K., Qutob D., and Chernys, J. T. (2001). A class I chitinase from soybean seed coat. J. Exp. Bot. 52, 2283-2289. doi: 10.1093/jexbot/52.365.2283

Gijzen, M., van Huystee, R., and Buzzell, R. I. (1993). Soybean seed coat peroxidase. Plant Physiol. 103, 1061-1066.

Grover, A. (2012). Plant chitinases: genetic diversity and physiological roles. Crit. Rev. Plant Sci. 31, 57-73. doi: 10.1080/07352689.2011.616043

Gutensohn, M., Fan, E., Frielingsdorf, S., Hanner, P., Hou, B., Hust, B., et al. (2006). Toc, Tic, Tat et al.: structure and function of protein transport machineries in chloroplasts. J. Plant Physiol. 163, 333-347. doi: 10.1016/j.jplph.2005.11.009

Haruta, M., Pedersen, J. A., and Constabel, C. P. (2001). Polyphenol oxidase and herbivore defense in trembling aspen (Populus tremuloides): cDNA cloning, expression, and potential substrates. Physiol. Plant. 112, 552-558. doi: 10.1034/j.1399-3054.2001.1120413.x

Hendry, G. A. F., Thompson, K., Moss, C. J., Edwards, E., and Thorpe, P. C. (1994), Seed persistence: a correlation between seed longevity in the soil and orthodihydroxyphenol concentration. Funct. Ecol. 8, 658-664. doi: 10.2307/2389929

Hiraga, S., Sasaki, K., Ito, H., Ohashi, Y., and Matsui, H. (2001). A large family of class III plant peroxidases. Plant Cell Physiol. 42, 462-468. doi: 10.1093/pcp/pce061

Hücklehoven, R. (2007). Cell wall-associated mechanisms of disease resistance and susceptibility. Annu. Rev. Phytopathol. 45, 101-127. doi: 10.1146/annurev.phyto.45.062806.094325

Hurkman, W. J., and Tanaka, C. K. (1996). Germin gene expression is induced in wheat leaves by powdery mildew infection. Plant Physiol. 111, 735-739.

Imai, K., and Nakai, K. (2010). Prediction of subcellular locations of proteins: where to proceed? Proteomics 10, 3970-3983. doi: 10.1002/pmic.201000274

International Wheat Genome Sequencing Consortium [IWGSC]. (2014). A chromosome-based draft sequence of the hexaploid bread wheat (Triticum aestivum) genome. Science 345:1251788. doi: 10.1126/science. 1251788

Jerkovic, A., Kriegel, A. M., Bradner, J. R., Atwell, B. J., Roberts, T. H., and Willows, R. D. (2010). Strategic distribution of protective proteins within bran layers of wheat protects the nutrient-rich endosperm. Plant Physiol. 152, 1459-1470. doi: $10.1104 / \mathrm{pp} .109 .149864$

Lane, B. G. (1994). Oxalate, germin, and the extracellular matrix of higher plants. FASEB J. 8, 294-301.

Lane, B. G. (2002). Oxalate, germins, and higher-plant pathogens. IUBMB Life 53, 67-75. doi: 10.1080/15216540211474

Lane, B. G., Bernier, F., Dratewka-Kos, E., Shafai, R., Kennedy, T. D., Pyne, C., et al. (1991). Homologies between members of the germin gene family in hexaploid wheat and similarities between these wheat germins and certain Physarum spherulins. J. Biol. Chem. 266, 10461-10469.

Lane, B. G., Dunwell, J. M., Ray, J. A., Schmitt, M. R., and Young, A. C. (1993). Germin, a protein marker of early plant development, is an oxalate oxidase J. Biol. Chem. 268, 12239-12242.

Laugesen, S., Bak-Jensen, K. S., Hägglund, P., Henriksen, A., Finnie, C. Svensson, B., et al. (2007). Barley peroxidase isozymes expression and posttranslational modification in mature seeds as identified by two-dimensional gel electrophoresis and mass spectrometry. Int. J. Mass Spectrom. 268, 244-253. doi: 10.1016/j.ijms.2007.06.003

Leah, R., Skriver, K., Knudsen, S., Ruud-Hansen, J., Raikhel, N. V., and Mundy, J. (1994). Identification of an enhancer/silencer sequence directing the aleurone-specific expression of a barley chitinase gene. Plant J. 6, 579-598. doi: 10.1046/j.1365-313X.1994.6040579.x

Liang, H., Maynard, C. A., Allen, R. D., and Powell, W. A. (2001). Increased Septoria musiva resistance in transgenic hybrid poplar leaves expressing a wheat oxalate oxidase gene. Plant Mol. Biol. 45, 619-629. doi: 10.1023/A:1010631318831

Long, R. L., Gorecki, M. J., Renton, M., Scott, J. K., Colville, L., Goggin, D. E., et al. (2014). The ecophysiology of seed persistence: a mechanistic view of the journey to germination or demise. Biol. Rev. Camb. Philos. Soc. doi: 10.1111/brv.12095 [Epub ahead of print].

Marles, M. A. S., Vandenberg, A., and Bett, K. E. (2008). Polyphenol oxidase activity and differential accumulation of polyphenolics in seed coats of pinto bean (Phaseolus vulgaris L.) characterize postharvest color changes. J. Agric. Food Chem. 56, 7049-7056. doi: 10.1021/jf8004367

Massa, A. N., Beecher, B., and Morris, C. F. (2007). Polyphenol oxidase (PPO) in wheat and wild relatives: molecular evidence for a multigene family. Theor. Appl. Genet. 114, 1239-1247. doi: 10.1007/s00122-007-0514-4

Matsumoto, T., Tanaka, T., Sakai, H., Amano, N., Kanamori, H., Kurita, K., etal. (2011). Comprehensive sequence analysis of 24,783 barley fulllength cDNAs derived from 12 clone libraries. Plant Physiol. 156, 20-28. doi: 10.1104/pp.110.171579

Mayer, A. M. (2006). Polyphenol oxidases in plants and fungi: going places? A review. Phytochemistry 67, 2318-2331. doi: 10.1016/j.phytochem.2006.08.006

Mohammadi, M., and Kazemi, H. (2002). Changes in peroxidase and polyphenol oxidase activities in susceptible and resistant wheat heads inoculated with Fusarium graminearum and induced resistance. Plant Sci. 162, 491-498. doi: 10.1016/S0168-9452(01)00538-6

Naylor, J. M., and Fedec, P. (1978). Dormancy studies in seed of Avena fatua. 8. Genetic diversity affecting response to temperature. Can. J. Bot. 54, 2224-2229. doi: $10.1139 / \mathrm{b} 78-267$

Newman, S. M., Tantasawat, P., and Steffens, J. C. (2011). Tomato polyphenol oxidase $B$ is spatially and temporally regulated during development and in response to ethylene. Molecules 16, 493-517. doi: 10.3390/molecules 16010493

Passardi, F., Cosio, C., Penel, C., and Dunand, C. (2005). Peroxidases have more functions than a Swiss army knife. Plant Cell Rep. 24, 255-265. doi: 10.1007/s00299-005-0972-6

Petersen, T. N., Brunak, S., von Heijne, G., and Nielsen, H. (2011). SignalP 4.0: discriminating signal peptides from transmembrane regions. Nat. Methods 8, 785-786. doi: 10.1038/nmeth.1701

Pimentel, D., Zuniga, R., and Morrison, D. (2005). Update on the environmental and economic costs associated with alien-invasive species in the United States. Ecol. Econ. 52, 273-288. doi: 10.1016/j.ecolecon.2004.10.002

Poiatti, V. A. D., Dalmas, F. R., and Astarita, L. V. (2009). Defense mechanisms of Solanum tuberosum L. in response to attack by plant-pathogenic bacteria. Biol. Res. 42, 205-215. doi: 10.4067/S0716-97602009000200009

Ramamoorthy, V., Raguchander, T., and Samiyappan, R. (2002). Induction of defense-related proteins in tomato roots treated with Pseudomonas fluorescens Pf1 and Fusarium oxysporum f. sp. lycopersici. Plant Soil 239, 55-68. doi: 10.1023/A:1014904815352

Rani, K. U., Prasada-Rao, U. J. S., Leelavathi, K., and Haridas-Rao, P. (2001). Distribution of enzymes in wheat flour mill streams. J. Cereal Sci. 34, 233-242. doi: $10.1006 /$ jcrs.2000.0393

Shen, H.-B., and Chou, K.-C. (2007). Signal-3L: a 3-layer approach for predicting signal peptides. Biochem. Biophys. Res. Commun. 363, 297-303. doi: 10.1016/j.bbrc.2007.08.140

Steffens, J. C., Harel, E., and Hunt, M. D. (1994). "Polyphenol oxidase," in Recent Advances in Phytochemistry, Genetic Engineering of Plant Secondary Metabolism, eds B. E. Ellis, G.W. Kuroki, and H. A. Stafford (New York: Plenum Press), 275312. doi: 10.1007/978-1-4615-2544-8_11

Thipyapong, P., Joel, D. M., and Steffens, J. C. (1997). Differential expression and turnover of the tomato polyphenol oxidase gene family during vegetative and reproductive development. Plant Physiol. 113, 707-718.

Thipyapong, P., Stout, M. J., and Attajarusit, J. (2007). Functional analysis of polyphenol oxidases by antisense/sense technology. Molecules 12, 1569-1595. doi: $10.3390 / 12081569$

Thygesen, P. W., Dry, I. B., and Robinson, S. P. (1995). Polyphenol oxidase in potato, a multigene family that exhibits differential expression patterns. Plant Physiol. 109, 525-531. doi: 10.1104/pp.109.2.525

Till-Bottraud, I., and Brabant, P. (1990). Inheritance of some Mendelian factors in intra- and interspective crosses between Setaria italic and Setaria viridis. Theor. Appl. Genet. 80, 687-692. doi: 10.1007/BF00224230

Tran, L. T., Taylor, J. S., and Constabel, C. P. (2012). The polyphenol oxidase gene family in plants: lineage-specific duplication and gene expansion. BMC Genomics 13:395. doi: 10.1186/1471-2164-13-395

Vadlamani, K. R., and Seib, P. A. (1996). Reduced browning in raw oriental noodles by heat and moisture treatment of wheat. Cereal Chem. 73, 88-95. 
van Gelder, C. W. G., Flurkey, W. H., and Wichers, H. J. (1997). Sequence and structural features of plant and fungal tyrosinases. Phytochemistry 45, 1309-1323. doi: 10.1016/S0031-9422(97)00186-6

van Loon, L. C., Rep, M., and Pieterse, C. M. J. (2006). Significance of inducible defense-related proteins in infected plants. Annu. Rev. Phytopathol. 44, 135-162. doi: 10.1146/annurev.phyto.44.070505.143425

Yan, R., Hou, J., Ding, D., Guan, W., Wang, C., Wu, Z., et al. (2008). In vitro antifungal activity and mechanism of action of chitinase against four plant pathogenic fungi. J. Basic Microbiol. 48, 293-301. doi: 10.1002/jobm.200700392

Yan, S., and Wu, G. (2014). Signal peptides of cellulose. Appl. Microbiol. Biotechnol. 98, 5329-5362. doi: 10.1007/s00253-014-5742-3

Yoruk, R., and Marshall, M. R. (2003). Physicochemical properties and function of plant polyphenol oxidase: A review. J. Food Biochem. 27, 361-422. doi: 10.1111/j.1745-4514.2003.tb00289.x

Zhang, X. Y., Nie, Z. H., Wang, W. J., Leung, D. W. M., Xu, D. G., Chen, B. L., et al. (2013). Relationship between disease resistance and rice oxalate oxidases in transgenic rice. PLoS ONE 8:e78348. doi: 10.1371/journal.pone.0078348
Conflict of Interest Statement: The authors declare that the research was conducted in the absence of any commercial or financial relationships that could be construed as a potential conflict of interest.

Received: 04 September 2014; accepted: 18 November 2014; published online: 10 December 2014.

Citation: Fuerst EP, Okubara PA, Anderson JV and Morris CF (2014) Polyphenol oxidase as a biochemical seed defense mechanism. Front. Plant Sci. 5:689. doi: 10.3389/fpls.2014.00689

This article was submitted to Plant Physiology, a section of the journal Frontiers in Plant Science.

Copyright (c) 2014 Fuerst, Okubara, Anderson and Morris. This is an open-access article distributed under the terms of the Creative Commons Attribution License (CC BY). The use, distribution or reproduction in other forums is permitted, provided the original author(s) or licensor are credited and that the original publication in this journal is cited, in accordance with accepted academic practice. No use, distribution or reproduction is permitted which does not comply with these terms. 